\title{
Referral of patients to an anticoagulant clinic: implications for better management
}

\author{
G B T Tan, H Cohen, F C Taylor, J Gabbay
}

Research Unit of the Royal College of Physicians,

London NW1 4LE and

Academic Department of Public Health. St Mary's Hospital Medical School, London W2 1PG

G B T Tan, clinical research fellow

F C Taylor, research assistant

Department of

Haematology,

St Mary's Hospital

Medical School,

London W2 1PG and

Central Middlesex

Hospital,

London NW10 7NS

$\mathrm{H}$ Cohen, senior lecturer

in haematology

Health Care

Development Unit, Central Middlesex Hospital,

London NW10 7NS

$\mathrm{J}$ Gabbay, professor in public health

Correspondence to: Ms F Taylor, Health Care Development Unit, The Bungalow, Central Middlesex Hospital, London NW10 7NS

Accepted for publication 26 February 1993
Abstract

The quality of anticoagulant treatment of ambulatory patients is affected by the content of referral letters and administrative processes. To assess these influences a method was developed to audit against the hospital standard the referral of patients to one hospital anticoagulant clinic in a prospective study of all (80) new patients referred to the clinic over eight months. Administrative information was provided by the clinic coordinator, and the referral letters were audited by the researchers. Referral letters were not received by the clinic for $10 \%(8 / 80)$ of patients. Among the 72 referral letters received, indication for anticoagulation and anticipated duration of treatment were specified in most $(99 \%$, 71 and $81 \%, 58$ respectively), but only $3 \%$ (two) to $46 \%$ (33) reported other important clinical information (objective investigations, date of starting anticoagulation, current anticoagulant dose, date and result of latest international normalised ratio, whether it should be the anticoagulant clinic that was eventually to stop anticoagulation, patients' other medical problems and concurrent treatment. Twenty two per cent $(16 / 80)$ of new attenders were unexpected at the anticoagulant clinic. Most patients' case notes were obtained for the appointment (61\%, $47 / 77$ beforehand and $30 \% \quad 23 / 77$ on the day), but case notes were not obtained for 9\% (7/77). The authors conclude that health professionals should better appreciate the administrative and organisational influences that affect team work and quality of care. Compliance with a well documented protocol remained below the acceptable standard. The quality of the referral process may be improved by using a more comprehensive and helpful referral form, which has been drawn up, and by educating referring doctors. Measures to increase the efficiency of the administrative process include telephoning the clinic coordinator directly, direct referrals through a computerised referral system, and telephone reminders by haematology office staff to ward staff to ensure availability of the hospital notes. The effect of these changes will be assessed in a repeat audit. (Quality in Health Care 1993;2:96-99)

\section{Introduction}

Oral anticoagulants are widely used to prevent and treat thromboembolic disease, but because the therapeutic range is narrow blood tests should be done regularly to monitor control. There is the risk of thromboembolism in under-anticoagulation and of haemorrhage, which can be life threatening, ${ }^{1}$ in overanticoagulation. Anticoagulant clinics have been developed to provide safe and efficient administration of oral anticoagulation treatment to ambulatory patients. Patients may be referred to an anticoagulant clinic before discharge from a hospital ward, directly from another outpatient clinic, or on discharge from another hospital where anticoagulation treatment was started but would not be followed up.

Evaluation of referrals to hospital has generated much interest lately, but most published work has been on referrals from general practitioners $(\mathrm{GPs})^{2}$ rather than referrals within a hospital. Most referrals to an anticoagulant clinic are from hospital doctors, and it is important to evaluate them rather than extrapolate inappropriate lessons from GP referrals. Previous research has also tended to focus on the quality of the referral communication $^{3}$ and not the referral process. For patients newly attending an anticoagulant clinic care is affected as much by the efficiency of the administrative arrangements for the first visit as by the clarity and completeness of the referral letter. These arrangements include how new appointments are ascertained and the availability of the referral letter and hospital notes at the first visit. These responsibilities usually involve nurses, clerks, and secretaries, and the impact on patient care should be appreciated by both clinicians and non-medical staff.

The study hospital, a 580 bed acute general hospital, has a weekly anticoagulant clinic supervised by a consultant haematologist. Hospital guidelines on the anticoagulant treatment of inpatients based on guidelines by the British Society for Haematology ${ }^{4}$ have been drawn up by a consultant haematologist after discussion at the hospital physicians' 
audit meetings. ${ }^{5}$ The guidelines recommend that the referral letter provide full clinical details: reason for anticoagulation, concurrent treatment, other relevant information (for example, history of peptic ulcer, abnormal liver function tests), expected duration of treatment, date and result of latest international normalised ratio (INR), and dose of warfarin, and that arrangements be made for the hospital notes and referral letter to be available at the patient's first visit to the anticoagulant clinic.

The aim of the study was to develop and use a method for auditing the referral of patients to the anticoagulant clinic and to test adherence to agreed guidelines. As part of this process an audit proforma was designed and was tested for reliability and usefulness and piloted for its applicability. With this proforma the current referral practice at this hospital was audited. The accepted standard was for total conformity to the guidelines for each patient referred.

\section{Methods}

An audit proforma was designed with questions on the administrative information in the referral letter (patient's particulars, source of referral, and date of letter), the clinical information in the letter (indication for anticoagulation, objective investigations, date of starting anticoagulation, duration of treatment, current anticoagulant dose, date and result of latest INR, whether eventually the anticoagulant clinic should decide to stop anticoagulation, and patient's other medical problems and concurrent treatment) as well as the administrative process (mode of referral, dates of referral and appointment, and availability of notes on day of appointment).

All patients newly referred to the anticoagulant clinic from August 1991 to March 1992 were entered into the study prospectively. Administrative information on each was noted prospectively by the chief phlebotomist (also the coordinator of the anticoagulant clinic), who also photocopied the referral letters.

The referral letters were evaluated by the researchers using the audit proforma. A pilot study was conducted on 20 patients, including a reliability study of the proforma questions by cross checking two independent auditors (FCT and GBTT) by $\kappa$ analysis. This analysis compares agreement between two observers classifying nominal categories, taking into

Table 1 Provision of clinical information in 72 referral letters. Figures are numbers (percentages)

\begin{tabular}{|c|c|c|c|}
\hline Item in letter & Yes & No & Ambiguous \\
\hline Indication & $71(99)$ & $1(3)$ & 0 \\
\hline Objective investigation(s) & $15(21)$ & $56(78)$ & $1(1)$ \\
\hline Expected duration of treatment & $58(81)$ & $14(19)$ & 0 \\
\hline Date anticoagulation started $\star$ & $2(3)$ & $68(94)$ & 0 \\
\hline Current anticoagulant dose $e^{\star}$ & $27(37)$ & $43(60)$ & 0 \\
\hline Date of latest international normalised ratio ${ }^{\star}$ & $10(14)$ & $60(83)$ & 0 \\
\hline Result of latest international normalised ratio* & $14(20)$ & $55(76)$ & $1(1)$ \\
\hline Who to stop anticoagulation ${ }^{\star}$ & $33(46)$ & $37(51)$ & 0 \\
\hline Other medical problems & $31(43)$ & 41(57) & 0 \\
\hline Concurrent treatment & $6(8)$ & $66(92)$ & 0 \\
\hline
\end{tabular}

ॠNot applicable in two patients in whom prophylactic anticoagulation was to be started at the anticoagulant clinic. account the agreement that might be expected by chance alone. ${ }^{6} 7$

\section{Results}

$\kappa$ ANALYSIS

There were 49 proforma questions; all were accepted as reliable because the $\kappa$ scores achieved a significance of $\mathrm{p}<0.01$.

\section{STUDY POPULATION}

The 80 patients admitted to the study comprised 31 females (39\%) and 49 males $(61 \%)$, with ages ranging from 9 to 89 years (median 60 years). The indications for anticoagulation were deep venous thrombosis $(\mathrm{n}=31,39 \%)$, pulmonary embolism $(\mathrm{n}=19$, $24 \%$ ), deep venous thrombosis with pulmonary embolism $(n=1,1 \%)$, atrial fibrillation ( $\mathrm{n}=11,14 \%)$, prosthetic cardiac valve $(\mathrm{n}=9,11 \%)$, peripheral artery embolism $(n=4,5 \%)$, and other less common diagnoses $(n=5,6 \%)$. Most patients were referred from within the hospital: $68(85 \%)$ were recent inpatients and five $(6 \%)$ were from an outpatient clinic; four $(5 \%)$ were referred from another hospital and three (4\%) from the GP.

\section{ADMINISTRATIVE INFORMATION}

Referral letters were never received for eight $(10 \%)$ patients. The patient's name was provided in the remaining 72 letters, the patient's age or date of birth in $62(86 \%)$, and the name of the referring doctor (hospital doctor or GP) in $66(92 \%)$; only $26(36 \%)$ letters were dated.

\section{CLINICAL INFORMATION}

The indication for anticoagulation and the anticipated duration of anticoagulant treatment were specified in most of the 72 referral letters $(99 \%$ and $81 \%$ respectively, table 1$)$. However, information on whether objective investigations were done, date of starting anticoagulant treatment, current dose of anticoagulant, date and result of latest INR, who was to stop anticoagulation, and whether patient had other concurrent medical problems or was receiving any other treatment were provided in only $3 \%$ to $46 \%$ of referral letters (table 1).

\section{ADMINISTRATIVE PROCESS}

Priority is placed on new referrals, so appointments are given for the earliest anticoagulant clinic. Sixteen $(22 \%)$ of the 80 patients presented for their first clinic attendance without the referring doctor having made prior arrangement with the clinic to expect them (that is, the appointment had not been made by the clinic). All had been recently discharged from the hospital wards, except one patient referred from an outpatient clinic and one from another hospital. Fifty seven $(89 \%)$ of the 64 patients with appointments attended the anticoagulant clinic on the arranged dates. The routine practice at this clinic is to send two further appointments to patients who fail to attend. Four $(6 \%)$ patients with appointments 
Table 2 Availability of hospital case notes for first attendance at anticoagulant clinic by 70 patients*

\begin{tabular}{|c|c|c|c|c|c|c|}
\hline \multirow[b]{2}{*}{ Time } & \multicolumn{2}{|c|}{ Notes sent to clinic by: } & \multicolumn{3}{|c|}{ Notes collected by clinic staff from: } & \multirow[b]{2}{*}{ Total } \\
\hline & $\begin{array}{l}\text { Ward } \\
\text { staff }\end{array}$ & $\begin{array}{c}\text { Records } \\
\text { department }\end{array}$ & $\begin{array}{l}\text { Medical } \\
\text { secretaries }\end{array}$ & $\begin{array}{c}\text { Haematology } \\
\text { department }\end{array}$ & $\begin{array}{c}\text { Records } \\
\text { department }\end{array}$ & \\
\hline $\begin{array}{l}\text { Before appointment date } \\
\text { On appointment date }\end{array}$ & $\begin{array}{l}44 \\
17\end{array}$ & $\begin{array}{l}0 \\
1\end{array}$ & $\begin{array}{l}3 \\
2\end{array}$ & $\begin{array}{l}0 \\
2\end{array}$ & $\begin{array}{l}0 \\
1\end{array}$ & $\begin{array}{l}47 \\
23\end{array}$ \\
\hline Total & & 62 & & 8 & & 70 \\
\hline
\end{tabular}

*These patients did not have previous hospital records and case notes were not found for seven patients.

attended between four to 28 days late for various reasons (for example, problems with ambulance transport), and three (5\%) failed ever to attend.

Fifty six ( $78 \%$ ) of the 72 referral letters were received before the appointment date, $14(19 \%)$ on that date, and two (3\%) after that date. The last letters were received only after the haematologist's written request that they be sent, with a resultant delay of two to three weeks to receipt after the patient's attendance. The eight patients for whom a referral letter was never received comprised six patients referred from the hospital wards (four from cardiothoracic teams and two from the haematology department), one patient referred from another hospital, and one from a GP.

Three patients did not have previous hospital records. Case notes were obtained before the appointment date for $47(61 \%)$ of the remaining 77 patients, on that date for $23(30 \%)$, but not at all for seven (9\%). Table 2 shows how and when the hospital case notes were obtained.

\section{Discussion}

Anticoagulant clinics function as a central facility to monitor the anticoagulant treatment of outpatients on behalf of referring clinicians. Continuity of patient care should ultimately be the responsibility of the referring clinician and should include a smooth introduction of the patient to the anticoagulant clinic. This can be achieved only by prompt provision of complete and accurate referral information. Shared care cannot be implemented successfully if key details such as the name of referring doctor (whether hospital doctor or GP) are not known, as in $12 \%$ of patients in our study.

Clinical information in referral letters helps the haematologist at the anticoagulant clinic to manage patients. Collecting omitted information requires extra consultation time in a busy clinic, and, even worse, omissions and ambiguities may be overlooked altogether. McInnes and Helenglass have cautioned that if indications for anticoagulation are unclear and the risks are unknown the time when anticoagulation should stop may pass unnoticed, so that anticoagulation continues by default. ${ }^{8}$ A recent study on communication between GPs and hospital consultants for clinic referrals concluded that the profession unanimously endorsed a standard for communication which its members could aspire to and use as a yardstick for their performance, as in the development of a "minimum requirement" for information in referral letters. ${ }^{9}$ Our results suggest that doctors referring patients do not fully appreciate the clinical significance of that minimum requirement for information, otherwise they would recognise the need to provide it. This emphasises the need to educate health professionals about the need to provide such information when care is being shared or taken over.

Regrettably, about a fifth of new patients presented at the clinic unexpectedly as a result of poor liaison between the referring doctor with responsibility for ensuring that an appointment had been made and the clinic. Poor communication from the hospital wards is particularly worrying and reinforces findings of our previous study on the inpatient management of anticoagulation. ${ }^{10} \mathrm{We}$ had noted that at discharge from the wards appointments for the anticoagulant clinic were documented in only $74 \%$ of the 60 patients continuing anticoagulant treatment. It is alarming that patients become lost to follow up after discharge, particularly if they continue their anticoagulant treatment with neither blood tests to monitor therapeutic control nor supervision to stop treatment at the appropriate time.

A major complaint by staff of the anticoagulant clinic is the chore of searching the hospital for missing medical notes, particularly during clinic time when they are already busy and understaffed. For the 23 clinic days of our study, the case notes of eight patients had to be collected by the clinic staff. The absence of case notes of five of these patients during clinic time resulted in disruption and fruitless searches as did searches for the case notes of seven other new attenders. This could have been prevented if ward staff had been aware of the patients' forthcoming appointments. The extra workload is substantial when added to the hunt for case notes of selected patients already attending the clinic.

CONCLUSIONS AND RECOMMENDATIONS FROM THE AUDIT

Audit often emphasises clinical practice (for example, the appropriate and timely use of anticoagulant treatment) rather than efficient administrative systems (for example, a system for handover of patients), yet the quality of patient care depends on teamwork among professionals and clerical staff at all levels. The most flawless referral letter can be undermined by failure to arrange a clinic appointment for the patient or by retaining the medical notes on the day of the appointment, thus negating the whole team's efforts to provide high quality care. Doctors often fail to appreciate the wider context of such team effort and that they are ultimately responsible for the sum total of that effort, which, as recently documented, must be integral to the overall quality of service. ${ }^{11}$

Although this study was conducted on the anticoagulant clinic, many of the lessons learnt can be applied to other specialist clinics. The results have been fed back to hospital staff to alert them to aspects of inadequate practice 


\section{Referral to anticoagulant clinic}

(Date of first clinic appointment )

Transport for the first appointment, if required, MUST be organised by the ward

\section{PATIENT'S PARTICULARS}

Name:

Address:

Date of birth:

(or addressograph label)

Telephone No of patient/neighbour:

Name and telephone No of GP:

REFERRAL INFORMATION

Referring consultant:

Reason for anticoagulation and precipitating factors:

Objective investigation(s) done for

$\begin{array}{ll}\text { DVT - venogram } \square & \text { ultrasound } \square \\ \text { Result: } & \\ {~-~} \quad \text { CXR } \square } & \text { Perfusion scan } \square \quad \text { V/Q scan } \square \\ \text { Result: } & \end{array}$

Date of starting warfarin:

Proposed duration of warfarin:

Do you wish the anticoagulant clinic

to stop warfarin at the end of this period? $\quad$ Yes $\square \quad$ No $\square$

Latest INR date and result:

Current warfarin dose, and since

when:

POTENTIAL HAZARDS

Risk factors to anticoagulation:

Other drugs (with doses):

Signature and name of referring

doctor and bleep number:

Please ensure that:

(1) An appointment for the anticoagulant clinic is arranged before discharge

(2) This referral form is received by the anticoagulant clinic BEFORE

appointment day

(3) Patient's medical notes are available for the anticoagulant clinic appointment

Form for referrals to anticoagulant clinic (DVT=deep venous thrombosis, $P E=$ pulmonary embolism, $C X R=$ chest $\mathrm{x}$ ray, $V / Q=v e n t i l a t i o n / p e r f u s i o n)$ and to provide continuing education. To improve both the administrative and clinical information in referral letters to the clinic we redesigned the internal referral form (box). We are arranging with the hospital computing unit for a modified version of the referral form to be generated in triplicate from ward terminals directly to the haematology department. The haematology office staff can then remind ward staff by telephone to ensure that the hospital notes are available at the clinic. This will minimise the workload of referring doctors while improving communication.

Access to the anticoagulant clinic is to be improved by circulating the coordinator's telephone number to the wards and by booking appointments at the anticoagulant clinic directly through the hospital computer system. This is particularly important when the time interval between referral and the clinic appointment is short or written communication through internal post is unreliable, or both.

Once these recommendations have been in place for another six months the audit will be repeated.

We thank the Research Unit, Royal College of Physicians (London) for funding this work, and Mrs Millie Simpson, anticoagulant clinic coordinator, for helping with the data collection. The audit proforma is available on request. 1 Charney R, Leddomado L, Rose DN, Fuster V. Anticoagulation clinics and the monitoring

2 Emmanuel J, Walter N. Referrals from general practice to hospital outpatient departments: a strategy for improvement. $B M \mathcal{F}$ 1989;299:722-4.

3 Westerman RF, Hull FM, Bezemer PD, Gort G. A study of communication between general practitioners and specialists. Br f Gen Prac 1990;40:445-9.

4 British Society for Haematology, British Committee for Standards in Haematology, Haemostasis and Thrombosis Task Force. Guidelines on oral anticoagulation: second edition. $\mathcal{F}$ Clin Pathol 1990;432:177-83.

5 Gabbay J, McNicol M, Spiby J, Davies SC, Layton AJ. What did medical audit achieve? Lessons from the preliminary evaluation of a year's medical audit. $B M \mathcal{F}$ 1990;301:526-9.

6 Fleiss J. Statistical methods for rates and proportions. London: Wiley, 1973.

7 Maclure M, Willett WC. Misinterpretation and misuse of Kappa. Am ₹ Epidemiol 1987;126:161-9.

8 McInnes GT, Helenglass G. The performance of clinics for outpatient control of anticoagulation. $\mathcal{F} R$ Coll Physicians Lond 1987;21:42-5.

9 Newton J, Eccles $\dot{M}$, Hutchinson A. Communication between general practitioners and consultants: what should letters contain? BMF 1992;304:821-4.

10 Tan G, Cohen H, Taylor F, Gabbay J. The audit of anticoagulation therapy: initiation of anticoagulation in inpatients. f Clin Path 1993;46:67-71.

11 Berwick D, Enthoven A, Bunker J. Quality management in the NHS: the doctor's role. II. $B M \mathcal{F} 1992 ; 304: 304-8$. 